ISSN 1112-9867

\title{
GAPS BETWEEN INDUSTRIALIST AND ACADEMIA IN COMMERCIALIZING RESEARCH PRODUCTS: INDUSTRIAL PERSPECTIVES
}

\author{
S. Zaini, N. Ismail ${ }^{*}$ and S. Sidek \\ Faculty of Technology Management and Technopreneurship, Universiti Teknikal Malaysia \\ Melaka, 75300 Melaka, Malaysia
}

Published online: 10 November 2017

\begin{abstract}
This study revealed that commercialization of research products in Malaysia is still not at satisfactory level. One of the reasons is due to the weak partnership between industrialist and academia in commercializing research products. As such, this paper aims to reduce the gap between industrialist and academia in commercializing research products. For this purpose, interview sessions with three industrialists were conducted. This paper found three important issues arise in partnership between industrialist and academia in commercializing research products. These issues are: (a) expensive charge of Intellectual Property, b) red tapes procedures and c) attitude of academia. By understanding these issues, the gap between industrialist and academia can be reduced and commercialization activities can be effectively achieved.
\end{abstract}

Keywords: industry-university collaboration; research products; commercialization.

Author Correspondence, e-mail: norain@utem.edu.my

doi: http://dx.doi.org/10.4314/jfas.v9i6s.68 


\section{INTRODUCTION}

As commonly agreed upon, universities are considered as a primary source of new knowledge for industry. This somehow demonstrates that the idea related to the industrialist-academia partnership is not something new. The past decade has seen rapid development of a partnership between industrialist and academia in the United States resulting from the industrial revolution in England and Germany, especially related to the British textile sector [11].

However, today, there are several other motives for both industrialist and academia to emphasize on when setting up a close partnership with each other. With such partnership, experts from various fields of knowledge and cutting-edge technology are accessible to industrial firms. According to [1], industrial firms can build up their corporate image and reputation. Besides, additional funding is also regarded to be a prime reason for the partnership between industrialist and academia since funding from industry is less bureaucratic and red tape than the federal or state governments.

For the quest of commercializing research products, partnership activities generally involves academia as the supplier of technology and the buyer, which is often a Small to Medium-sized Enterprise (SME). A study by [1] shows that the partnership between industrialist and academia has substantially increased in recent years. In [1]emphasized that the increased emphasis on a partnership is due to the combination of pressure on both; industrialist and academia. For the academia, the pressure includes the challenge of rising costs and growth in new knowledge meanwhile for industrialist, the pressure includes the rapid technological change, shorter product life cycles and intense global competition. The pressure on both parties has led to an increasing stimulus in developing a partnership between industrialist and academia.

In a study, in [10] stated that the partnership between industrialist and academia serves as a strategic approach for the success of research products commercialization. Instead of helping academia to secure funding, academia can create a product that meets the industry requirement and the industrialist can keep abreast with new technology in order to maintain competitive measures with their rivals. Such exchange of benefits thus makes this kind of relationship preferable. 
The initiative towards commercialization of research products is not new in Malaysia. In [3] said that many initiatives have been approached to increase the rate of commercialization research products in the country.However, the commercialization rate of research products is still not at satisfactory level. According to [4], in the 9th Malaysia Plan (2006-2010) and the 10th Malaysia Plan (2011-2015), the government had spent RM795 million into 1,675 approved research and development (R\&D) projects during the period. Unfortunately, only 487 projects were completed and 54 projects were successfully commercialized. These made the commercialization rate during the Ninth Malaysia Plan and the Tenth Malaysia Plan to be 8.3\% only (Bong, 2015). The circumstances proved that many universities in Malaysia are swamped with research products but very few end with commercialization.

According to [13], one of the prime reasons is due to the weakness of partnership between industrialist and academia. Universities which are the center of the best minds and consist of experts in various fields of specific knowledge are vaguely known to the industry. In fact, they are not fully utilized for the betterment of the society [10]. In [5] claimed that establishing a partnership between industrialist and academia is not an easy task. This type of partnership is generally driven by different motivations, priorities and cultures [6-7]. Universities prefer to deliver knowledge and publish their research results, whilst industry tends to keep the research findings secretly to avoid their rivals from gaining the information [2]. Furthermore, the conflicting understanding between the two parties makes it difficult for them to establish trust with each other [8]. This weakness of partnership makes research products difficult to be commercialized.

Hence, it is essential for academia to understand the barriers that inhibit the partnership with industrialist in order to plan a strategic action in driving the university towards a successful research products commercialization. Thus, from the perspective of the industrialist, this paper aims to investigate the barriers that obstruct the partnership between industrialist and academia in commercializing research products.

For that purpose, this paper is organized into four sections. After the introduction section, this paper describes the research methodology that captured the findings. The third section reports on the findings and presents the discussion of the study. Finally, this paper ends with a conclusion relating to three main issues that arise in the effort towards a partnership between 
industrialist and academia in commercialization research products endeavor. The issues are a) expensive charge of Intellectual Property (IP), b) red tapes procedures and c) attitude of academia.

\section{METHODOLOGY}

A qualitative research method was adopted to identify the issues that hamper the partnership between industrialist and academia. In this paper, interviews with three industrialists were conducted. The selection of the industrialists to be interviewed was based on a purposive sampling. Purposive sampling enables the researcher to use his judgement in deciding and selecting the cases that will best answer the research question and meet the objective of this paper. The three industrialists were purposely selected from industrialists who are experienced in partnership with their universities in commercializing research products. In this paper, the three industrialists are identified as Manager A, B and C for the purpose of anonymity. To capture an in-depth understanding of the barriers that obstruct the partnership, face-to-face interviews were carried out using semi-structured interview questions. The semi-structured interview enables the researcher to 'probe' answers, where this study seeks for respondents to explain their responses in order to understand the meanings. The opportunity to probe these meanings will add significance and depth to the data obtained [12]. The interviews typically lasted between 30 minutes and one hour. During each interview, the conversation was tape-recorded. The tape recording allowed all answers to be accurately gathered for the purpose of transcription. After each interview session, the interview data were transcribed word by word from the recording. After the transcription was completed, the researcher read and analyzed the transcript qualitatively. A thematic approach was employed to organize and analyze the data. In presenting the data, descriptions and direct quotations are deemed essential to allow the readers enter into the situation and thoughts of the participants represented in the findings [9]. Thus, descriptions and quotations were used in presenting the findings in this paper.

\section{RESULTS AND DISCUSSION}

From the perspective of industrialist, three main issues which hinder the partnership between industrialist and academia in commercializing research products arose. These issues are 
presented in Fig. 1.

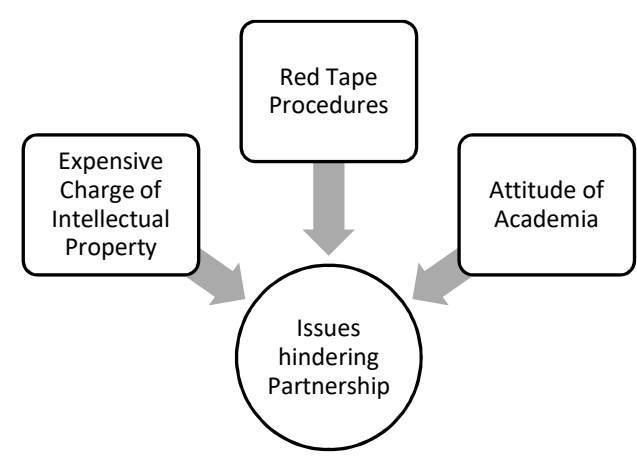

Fig.1. Issues hindering partnership from the industrial's perspective

As shown in Fig. 1, the issues that generally obstruct the partnership from industrial perspectives are; a) expensive charge of Intellectual Property (IP), b) red tape procedures and c) attitude of academia. Each of the issue is discussed as follows.

\subsection{Expensive Charge of Intellectual Property (IP)}

Conflict of Intellectual Property (IP) always appears in the shape of an argument between industrialist and academia partnership. There are few cases where issues of IP depict unsolvable problems and limit the expected relation between industrialist and academia. The industry claimed that the expensive charge of IP by universities is one of the factors that hampers the partnership. Increased focus on licensing and patenting acts as a constraint in the commercialization of research products. According to Manager C,

"Some industrialist, they do not prefer to collaborate with academia due to the expensive charge of IP $[\ldots]$ university imposed a very high royalties which at the end give minimum return to the industry itself' (Manager C)

Manager $\mathrm{C}$ claimed that the charge of IP imposed by universities is too expensive. The expensive charge of IP and the high royalties requested by universities are found to be not relevant to industry because they result in a negative return of investment. Therefore, this study viewed the expensive charge of IP as one of the barriers that obstruct industry to collaborate with academia in commercializing research products.

In general, IP charges depend on the production cost of the research products as well as the cost of issuing the IP. Nonetheless, universities should come to realization that imposing unreasonable fee can inhibit the marketing activities. On the contrary, undervaluing the 
research products will risk the universities from gaining the extra financial support. Thus, for this matter, universities need to look into various relevant factors before deciding on the license charge. This is to ensure that the industry that acts as a licensee be offered an optimal structure and a fair consideration of licensing service. Eventually, such two-way exchange of knowledge from both parties can result in shared advantage.

\subsection{Red Tape Procedures}

Too many bureaucracies with red tape procedures by universities also appeared to be one of the barriers that impedes the partnership between industrialist and academia in commercializing research products. According to Manager B,

"The process and procedures imposed by university is too complex. Some industry, they want everything to be fast $[\ldots]$ however, the process of achieving collaboration with university is complicated and slow [...] in term of agreement and so forth"(Manager B)

Manager B said that the process of achieving an agreement to collaborate with the universities is very complex. Industry generally works in an effective way which minimizes any unnecessary procedures. Creating bureaucracy will cause hurdles for industrialist to do an engagement with academia. Bureaucracy causes delay in work and industrialist cannot wait for long to complete their work. The lengthening of work duration causes industrialist to lose their jobs. With the red tape procedures and too many bureaucracies enforced by universities make it difficult for industrialist to achieve a partnership with academia in commercializing research products.

Henceforth, the partnership between academia and industrialist requires assistance in terms of established and proper procedures. To reduce the procedures as well as eradicate their stringency and hassle, technological development must be optimized. Apart from that, universities' receptivity and incentives not only ease the process of partnership but also become the platform for research products commercialization to succeed. In due course, a bountiful of university research products can be flourishingly marketed.

\subsection{Attitude of Academia}

Another barrier facing by industrialist in collaborating with academia is the attitude of academia which is viewed as unpleasant by industrialist. Industrialist pointed out that 
academia is too arrogant and proud with the research products that they invented hence become less tolerant in dealing with industry.

"When we talked about collaboration, "who need who?" that is the difficulties. It is like they (academia) feel that they are high $[. .$.$] we are like, owe something from them [\ldots]$ that is why they enforce so many complicated condition to fulfil." (Manager A)

Industry felt that academia is not giving a proper treatment to them. The approach of academia in dealing with industry is claimed to be very poor. Lack of academia's appreciation on the responsibility of the industry to their universities lead to difficulties in partnership between industrialist and academia in commercializing research products.

As academia and industrialist belonged to two different working environments, partnership is indeed achieved based on their strengths. While industrialist owns the equipment, academia has the advantage of access to a pool of researchers. The result of such skill-sharing has an impact on the partnership. To ensure that the two organizations develop a positive relationship, they should be clear of their job scope and meet often. By doing so, not only disputes between them can be abstained, but also make them realize of each other's importance in reaching shared goals.

\section{CONCLUSION}

Based on the industrial's perspective, this paper addresses three barriers that impede the partnership between industrialist and academia in commercializing research products. These barriers are: a) expensive charge of Intellectual Property (IP), b) red tape procedures and c) attitude of academia. The barriers indicate the importance for academia to work together with industrialist in overcoming barriers and solving problems. For the quest of commercialization, academia should ease the process of partnering with industrialist so that collaboration can be achieved in accelerating commercialization activities. On the other hand, industrialist should tolerate and adopt a flexible approach in dealing with the bureaucracy implemented by universities. By having a high level of understanding, flexibility, tolerance and frequent communication, a success partnership between industrialist and academia can be achieved and commercialization of research products can be materialized. 


\section{ACKNOWLEDGEMENTS}

This study is part of the findings of the FRGS Project Code: FRGS/1/2014/SS05/FPTT/02/F0026.

\section{REFERENCES}

[1] Ankrah S, Al-Tabbaa O. Universities-industry collaboration: A systematic review. Scandinavian Journal of Management, 2015, 31(3):387-408

[2] Aziati A, Hazana A, Ping T Y. Knowledge transfer of university-industry partnership in Malaysian Technical University: Preliminary findings. In IEEE International Symposium on Technology Management and Emerging Technologies, 2014, pp. 205-211

[3] Aziz A, Harris K, Zahid H, Aziz N. Commercialisation of university research: An investigation of researchers' behaviour. Communications of IBIMA, 2013, 2013:1-19

[4] BongK.Malaysia aims for 15 pct commercialisation rate. The Borneo Post, 2015, http://www.theborneopost.com/2015/04/15/malaysia-aims-for-15-pct-commercialisation-rate/

[5] Bruneel J, D'Este P, Salter A. Investigating the factors that diminish the barriers to university-industry collaboration. Research Policy, 2010, 39(7):858-868

[6] D’Este P, Perkmann M. Why do academics engage with industry? The entrepreneurial university and individual motivations. Journal of Technology, 2010, 36(3):316-339

[7] Howitt P. From curiosity to wealth creation: Howuniversity research can boost economic growth.

2013,https://www.cdhowe.org/sites/default/files/attachments/research_papers/mixed/Commen tary_383_0.pdf

[8] Othman N, Malek N.University-industry partnership: Understanding the current situation between UMP and DRB-HICOM.American Journal of Economics, 2012, 2012(Special Issue): $18-21$

[9] Patton M. Q. Qualitative research and evaluation methods. California: Sage Publications, 2002

[10]Ramli N, Zainol Z. University-industry collaboration: A catalyst towards entrepreneurial university. In Persidangan Kebangsaan Ekonomi Malaysia ke VIII, 2013, pp. 1227-1233

[11] Sanford L. The intellectual origins and new-worldliness of American industry. Journal of Economic History, 1958, 18(1):1-6 
[12]Saunders M., Lewis P., Thornhill A. Research methods for business students. England: Pearson, 2012

[13] Yaakob N, Hussain W, Rahman M, Zainol Z, Mujani W, Jamsari E, Sulaiman A,Jusoff $\mathrm{K}$. Challenges for commercialization of university research for agricultural based invention. World Applied Sciences Journal, 2011, 12(2):132-138

\section{How to cite this article:}

Zaini S, Ismail N, Sidek S. Gaps between industrialist and academia in commercializing research products: industrial perspectives. J. Fundam. Appl. Sci., 2017, 9(6S), 917-925. 